\title{
Symbolism And Consumer Acceptance: A Case Study Of Emojis And Food Choices.
}

\author{
Dr. Jyoti D. Vora ${ }^{1}$, Ms. Shruti Bendre ${ }^{2}$, Ms. Snigdha Mathure ${ }^{3}$ \\ Department of Biochemistry \& Food Science and Quality Control Ramnarain Ruia College, Matunga, Mumbai- \\ 400019
}

\begin{abstract}
Symbolism and emotional manifestation are completely synergistic phenomena. They can be scientifically extrapolated to food experiences, food preferences, consumerism and to an individual subject's general approach to food. The manner, in which a food preparation looks on the plate, is what tempts the viewer's eyes and makes the individual desire to taste it. Many nascent factors contribute to the complete perception of the appearance of a food product. This total perception is built up from all the visual sensations experienced when a product is viewed on the shelf, when it is being prepared and finally, when it is presented to the consumer. All three situations are extremely important to the consumer and hence to the manufacturer. These factors have encouraged us to consider objectively, the whole philosophy of product appearance and symbolic correlation. Although sight is not technically part of taste, it certainly influences perception. To our brains, "taste" is actually a fusion of a food's gustation, smell and touch into a single sensation. In reality, the physical act of ingestion plays only a small part in our choice of food, and in fact, most of our food choices are based on visual perceptions. The New Age of Technology has generated the creative use of Emojis or Emoticons to depict a "Food mood". These are commonly being used in the WhatsApp parlance by one and all. It seems intriguing that a small, colourful food emoticon can represent so much. We already use various foods emoticons for a number of different reasons. The steaming cup of coffee, the birthday cake with candles lit on top, the box of chocolates apparently as a gift or the delicacies of various cuisines which are a favourite for you and your friends, family and beloved. Food icons are one of the best ways to plan a treat, convey what you are thinking or planning. Naturally, this representation and symbolism has far reaching commercial, consumer-preference and clinical applications. This study is an attempt at generating a scientific and organoleptic inter-connection between food symbols and food perspectives using WhatsApp emoticons. A survey consisting of a structure, thematic and selfadministered questionnaire was used as part of the research methodology. The subjects used for the research endeavour were from different age groups; however, the major population was that of college going students with an age of around 20 years. This survey provides a link between consumer perspectives with reference to food labels and food choices. This study also includes various biochemical and anthropological variables such as age, blood group, lifestyle and gender. These have been correlated in the course of the study to establish a better connection between food symbolism and food perspectives. The application and extension of this study includes multi-disciplinary fields such as Quality Control, Food Packaging, Food Marketing, Innovative Product Designing and Quality Control. Such assessment is essential as the food choices of a person can affect the health and nutritional status and finally the psychosomatic profile of an individual most emphatically.
\end{abstract}

Keywords: WhatsApp, Emoji, Emoticons, Consumerism, Food Choices

\section{INTRODUCTION}

We are what we eat. This is scientifically proven as our food choices affect our health in every possible way. We, being Homo Sapiens, the thinking species have an emotional aspect towards food and food choices. It is said that there is no love more pure and true than the love for food. The food we eat is responsible for the functioning of every cell i.e $10^{14}$ cells in our body. So, our consumed food, being the monarch of the entire working system, the choice of food and likewise its consumption should be given the royal treatment equally for a healthy functioning body. In the most common way food is defined as any substance consumed to provide nutritional support for the body. It is usually of plant or animal origin, and contains essential nutrients, such as carbohydrates, fats, proteins, vitamins, or minerals. The substance is ingested by an organism and assimilated by the organism's cells to provide energy, maintain life, or stimulate growth. Food and emotions have been reported to share a bidirectional relationship: on the one hand, emotions can shape food choice, food intake and liking; while, on the other hand, food consumption can influence consumers' mood and emotions. 
A hungry man and a satiated person do not look at a loaf of bread in the same way. Therefore, it can be said that no two people have the same choices towards food and an individual's response greatly depends on their emotional perspectives towards food. Experiments have shown that in human memory recall, pictures outperform texts dramatically. When information is presented orally, after 3 days, people will remember only $10 \%$ of it. Whereas if you add a picture to it, this number jumps to about $65 \%$. This is known as pictorial superiority effect. The current research contributes to develop an interrelation with the use of emoticons and consumer acceptance by building new insights regarding consumer's spontaneous expressions of food related emotional experiences. The application and extension of this study includes multi-disciplinary fields such as Quality Control, Food Packaging, Food Marketing, and Innovative Product Designing.

Such assessment is essential as the food choices of a person can affect the health and nutritional status and finally the psychosomatic profile of an individual most emphatically.

\section{METHODOLOGY}

The study was carried out by administering questionnaires which form important and easy statistical tool for gathering information from the respondents. The results from such tools can be easily quantified and analysed and can be used to compare and contrast any existing studies.

\subsection{Preparation of Questionnaire}

Ten emoticons were selected which were thought to have an emphatic correlation with food expressions. It was seen that these selected emoticons were the most frequently used food emoticons and were studied accordingly. A questionnaire consisting about Twenty questions was prepared using those emoticons Apart from the twenty food- emoticon related questions, the questionnaire also consisted of different variables pertaining to the subjects like age, gender, diet preferences, blood group etc. These questionnaires were administered to thirty subjects who were college going students of age, eighteen to twenty-four years. Results from the present research were analysed and are expected to provide insights on how consumers spontaneously express emotional reactions to various food products and to study the interdependence of usage of emoticons with food symbolism.

\subsection{Data Analysis}

The data collected from the self-administered questionnaires was collated and the analysis was carried out by determining the frequency of use of each emoticon and 'emoji'. The frequencies were determined by counting the number of responses for the respective questions. Frequencies were calculated at the aggregate level. The results were tabulated and presented in the form of charts.

\section{RESULTS}

3.1 The following tables present a summary of the emoticon and emoji usage in the analysed questionnaires with reference to food symbolism.

\section{RESPONSES OF SUBJECTS ON USAGE OF WHATSAPP}

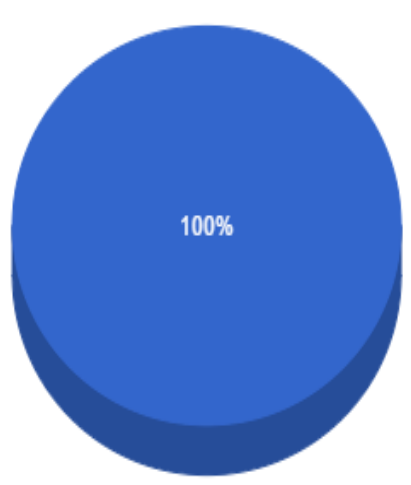

Use Whatsapp 
Figure 1: Responses of subjects on the use of WhatsApp

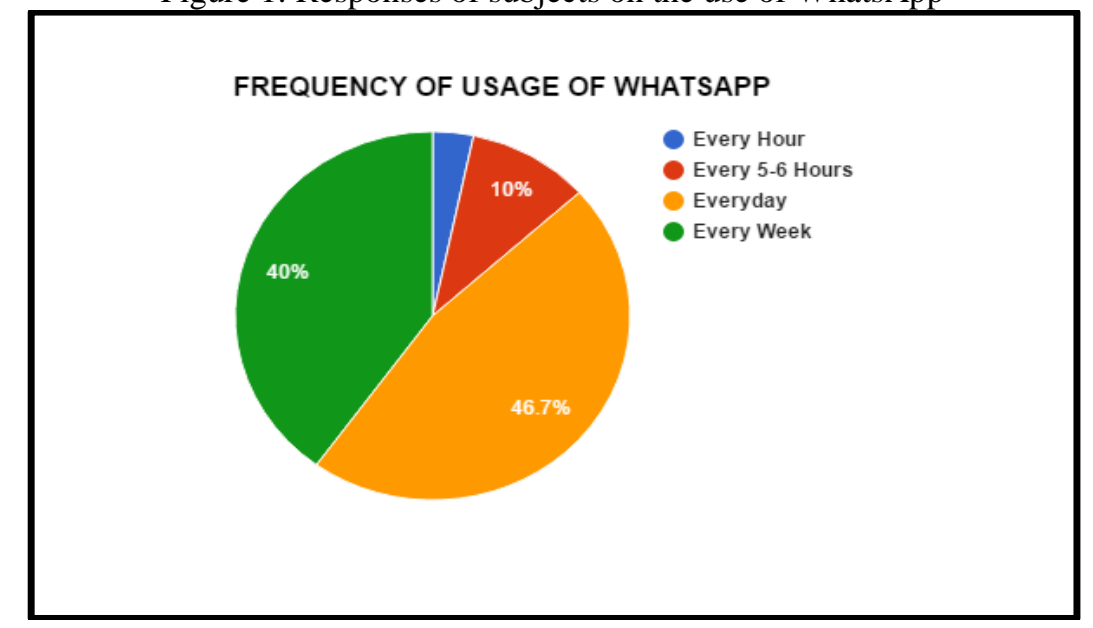

Figure 2: Frequency of usage of WhatsApp

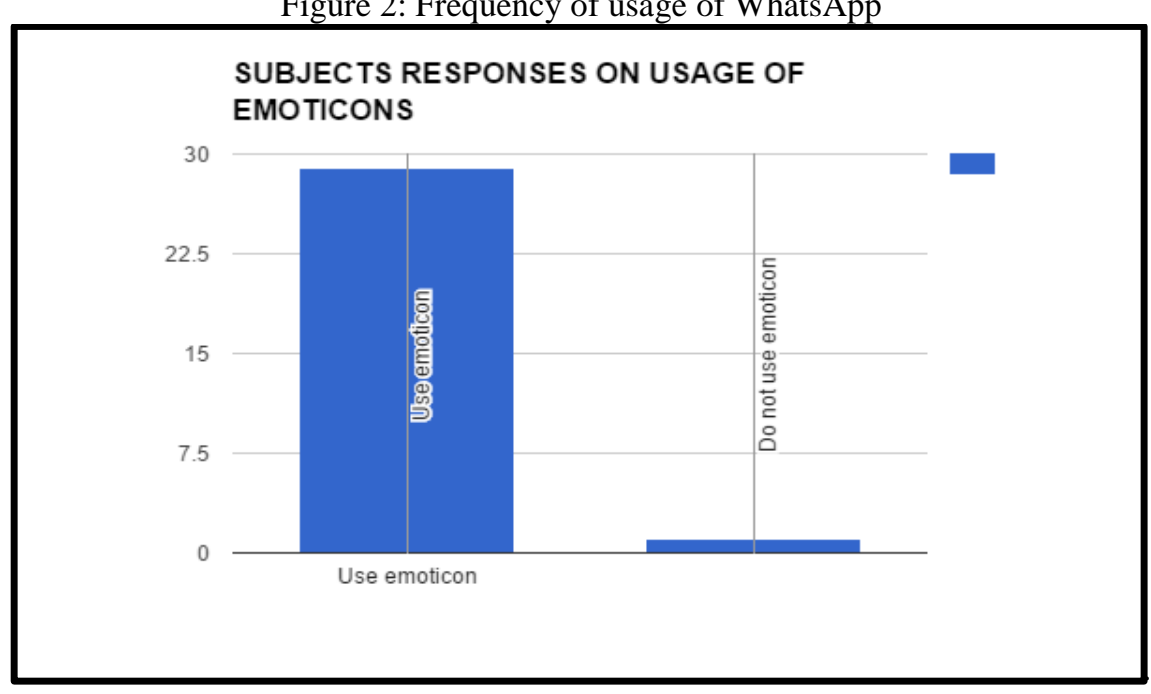

Figure 3: Subjects responses on usage of WhatsApp

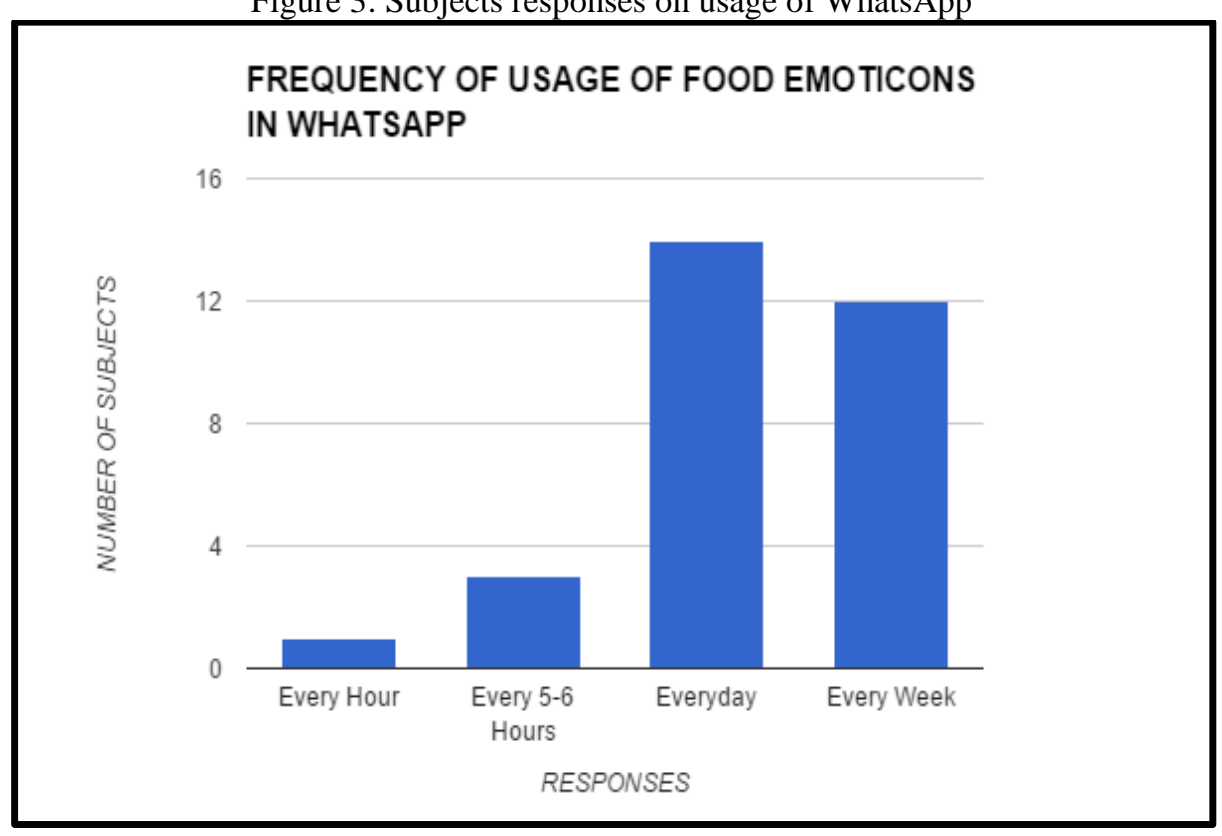

Figure 4: Frequency of usage of food emoticons in WhatsApp. 


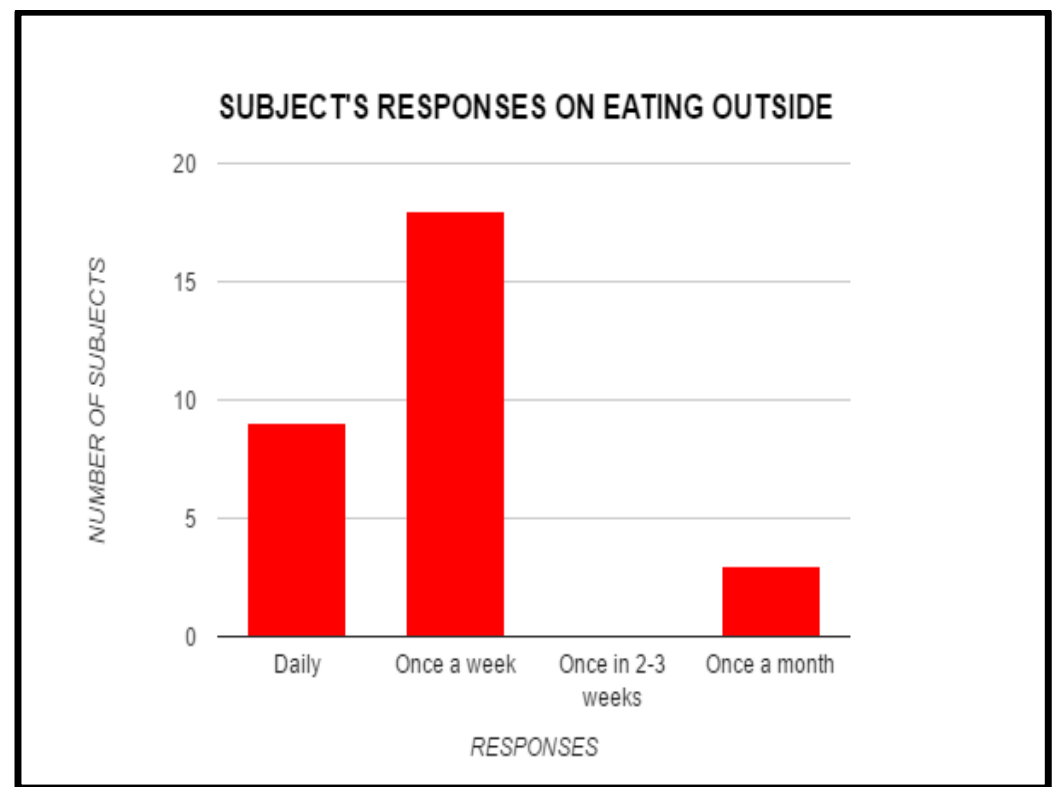

Figure 5: Subject's responses on eating outside.

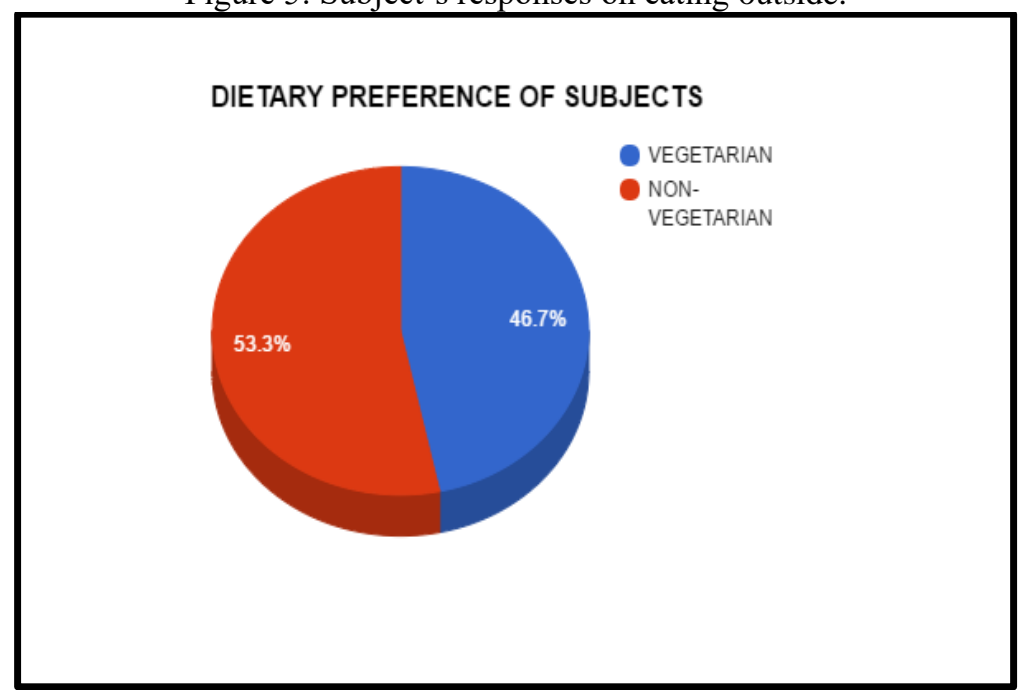

Figure $6:$ Dietary preference of subjects

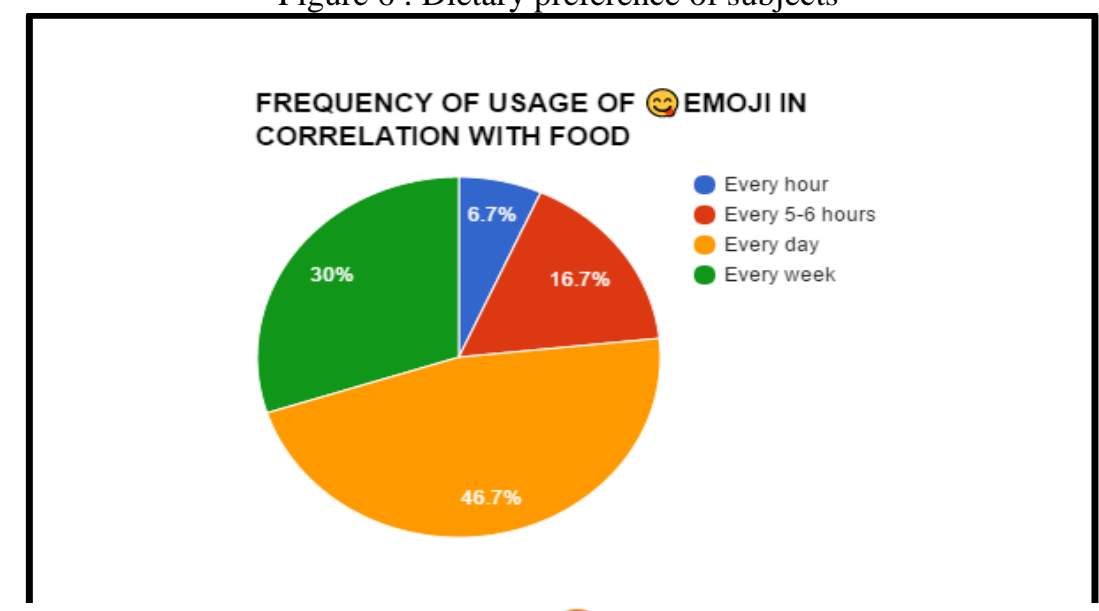

Figure 7 : Frequency of usage of emoji in correlation with food 


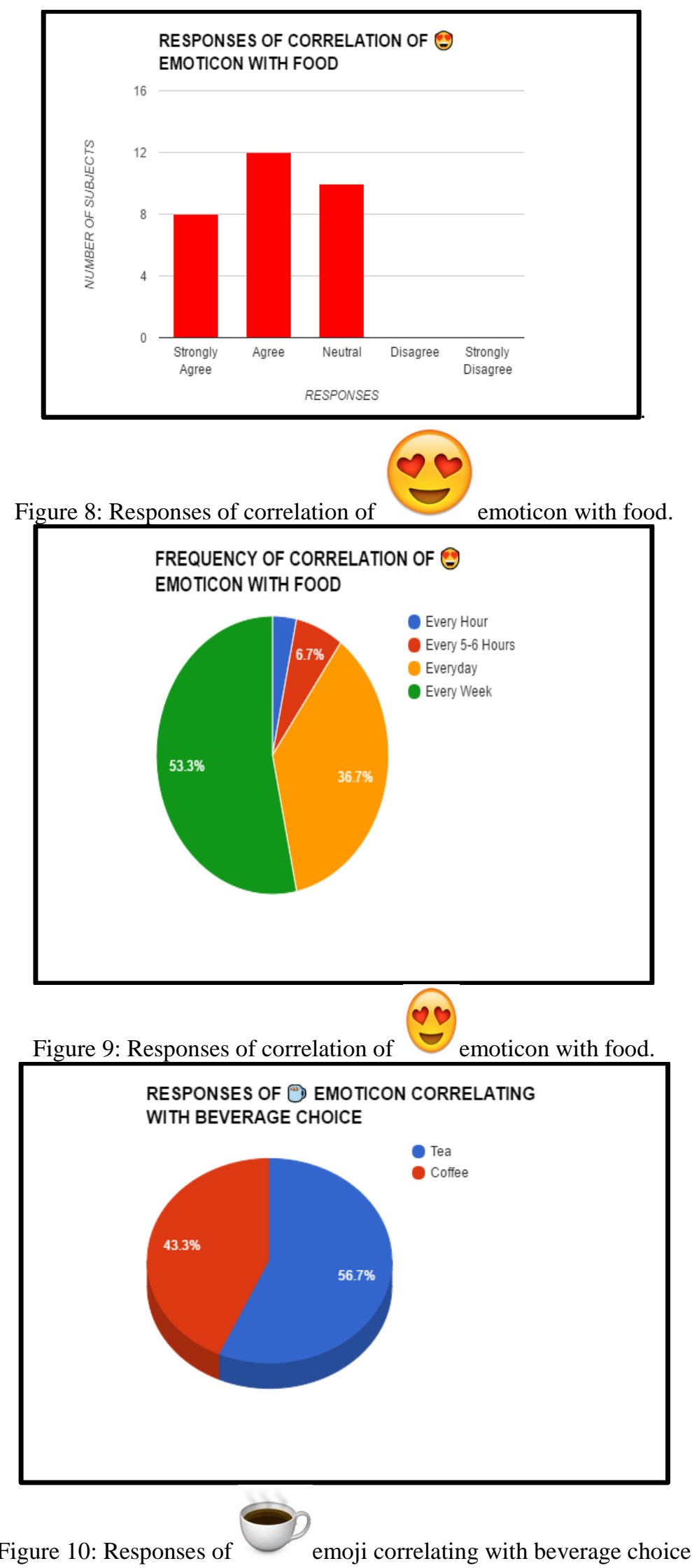

Figure 10: Responses of emoji correlating with beverage choice 


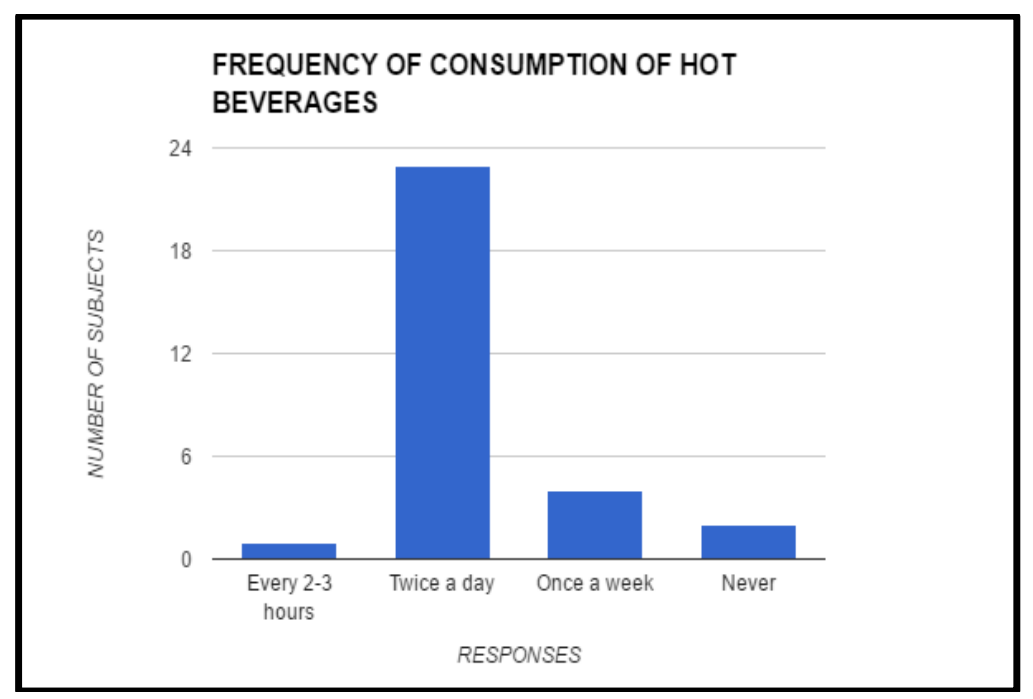

Figure 11 : Frequency of consumption of hot beverages

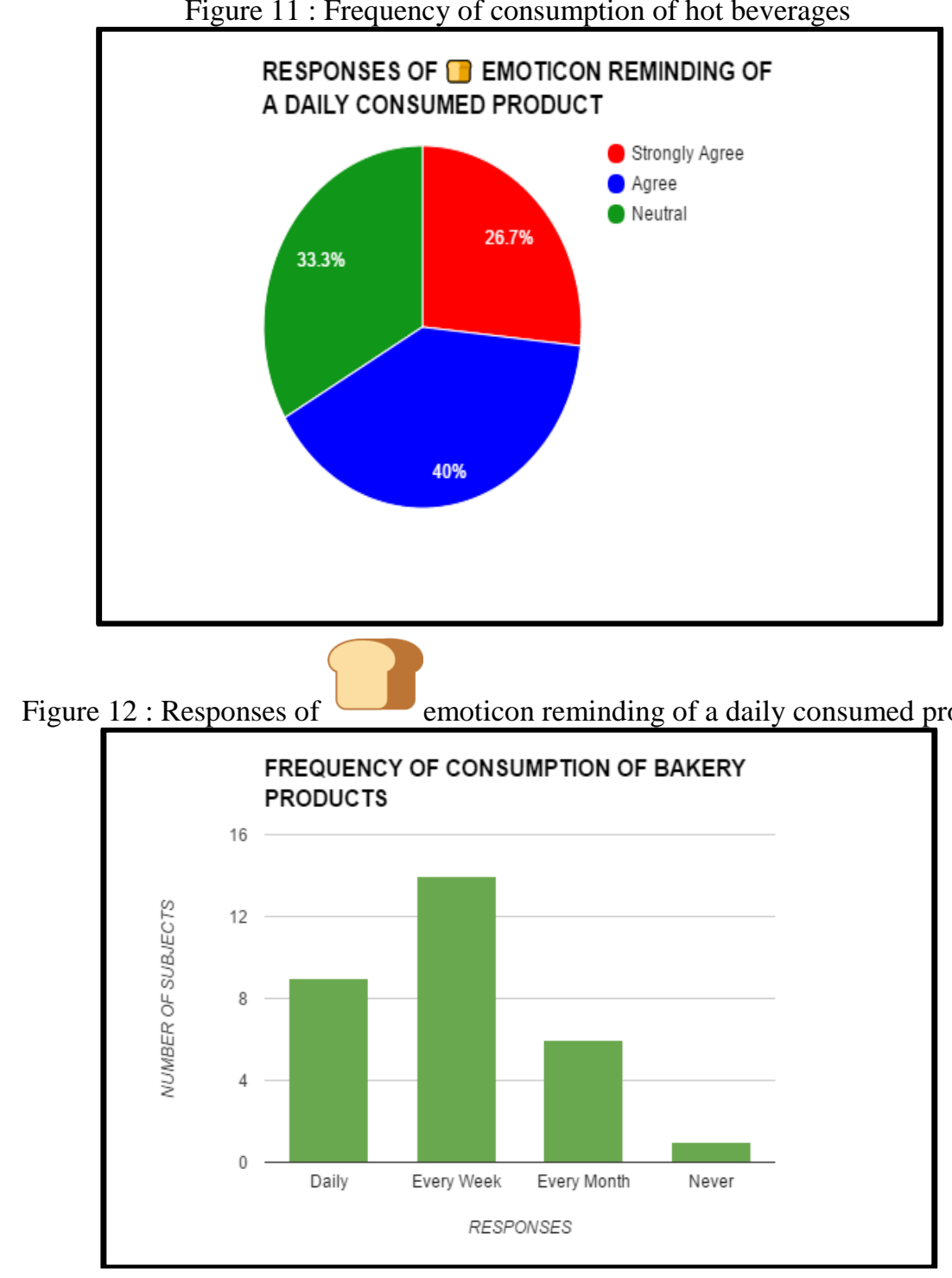

Figure 13: Frequency of consumption of bakery products. 


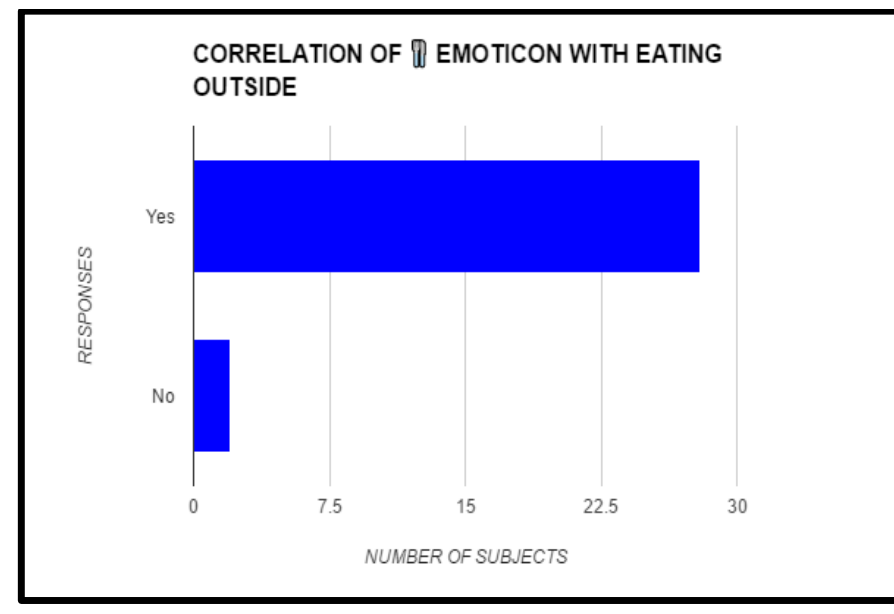

CORRELATION OF W EMOTICON WITH EATING

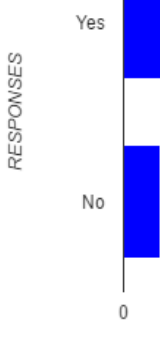

NUMBER OF SUBJECTS

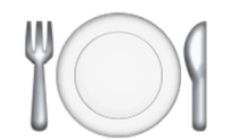

Figure 14: Correlation of

emoticon with eating outside.

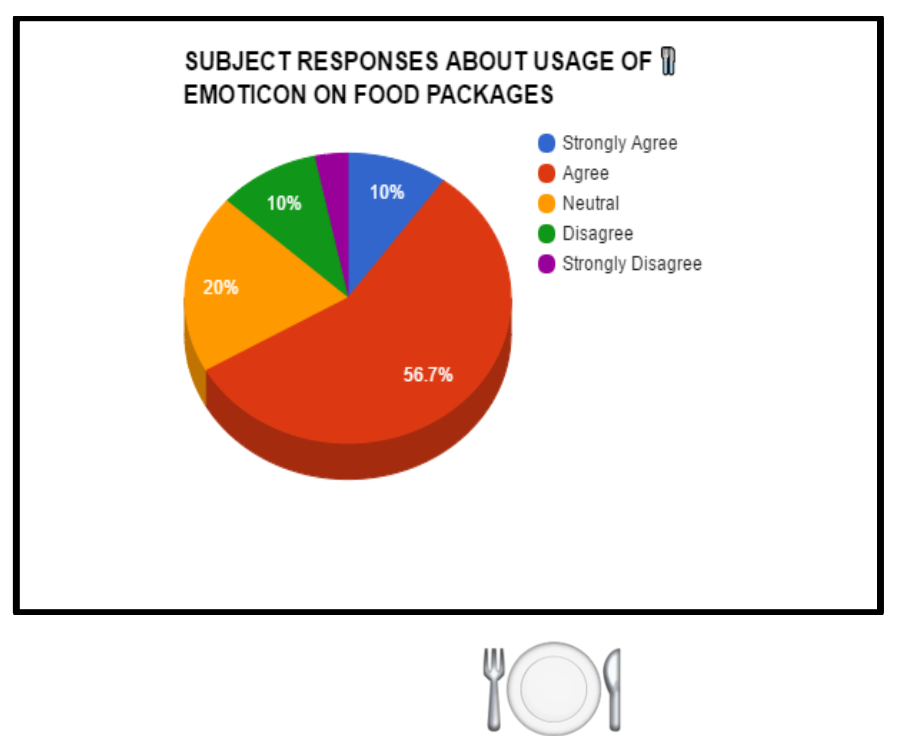

Figure 15 : Subject responses on usage of emoticon on food package.

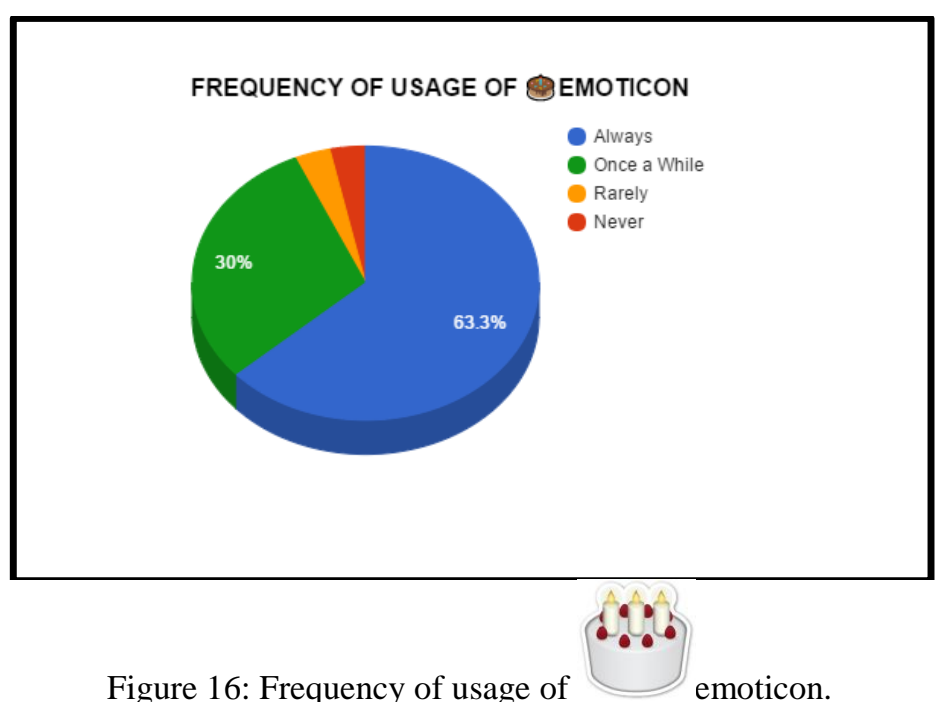

Figure 16: Frequency of usage of

emoticon. 

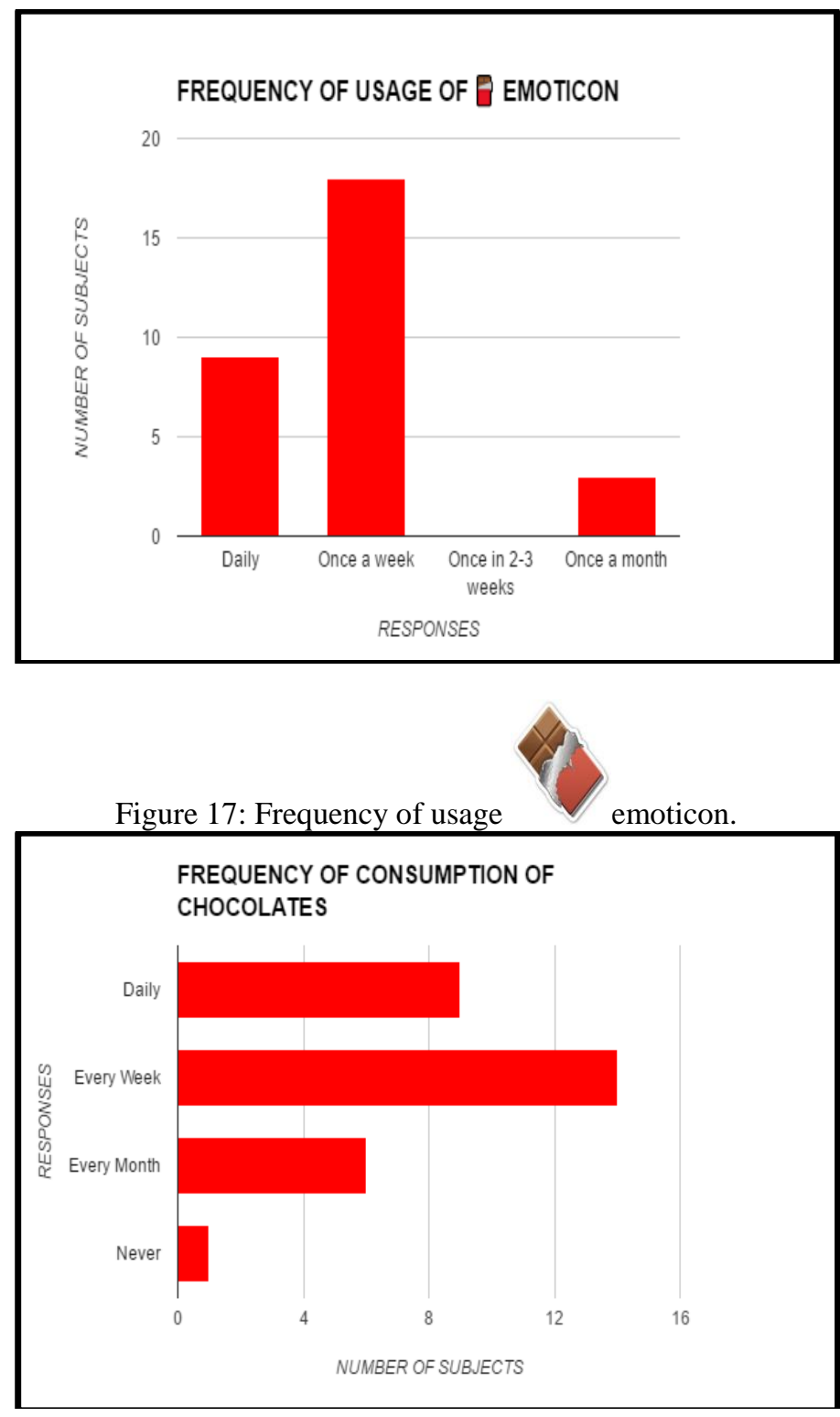

Figure 18: Frequency of consumption chocolates

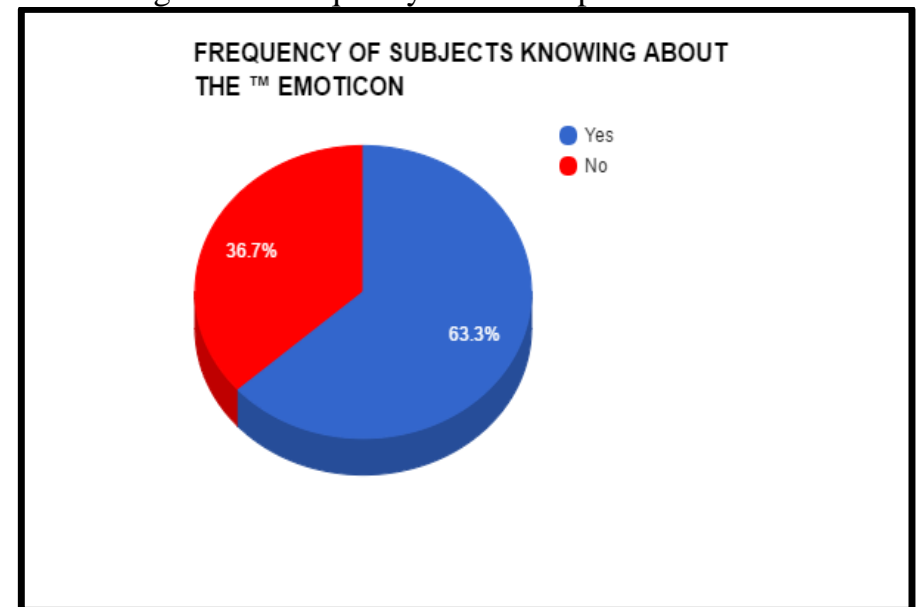

Figure 19: Frequency of subjects knowing about the

TM emoticon. 


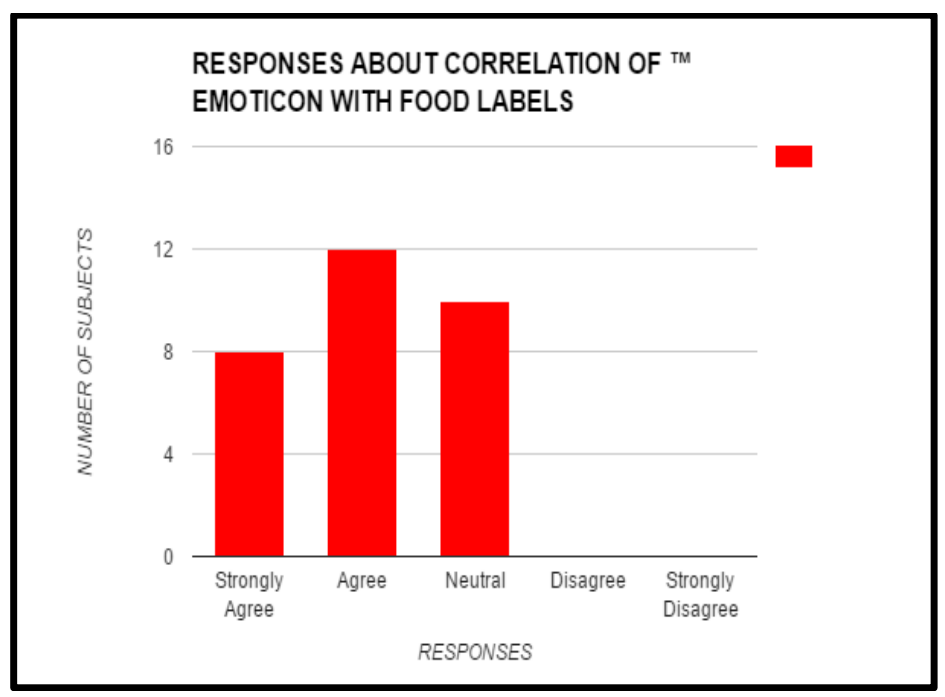

TM

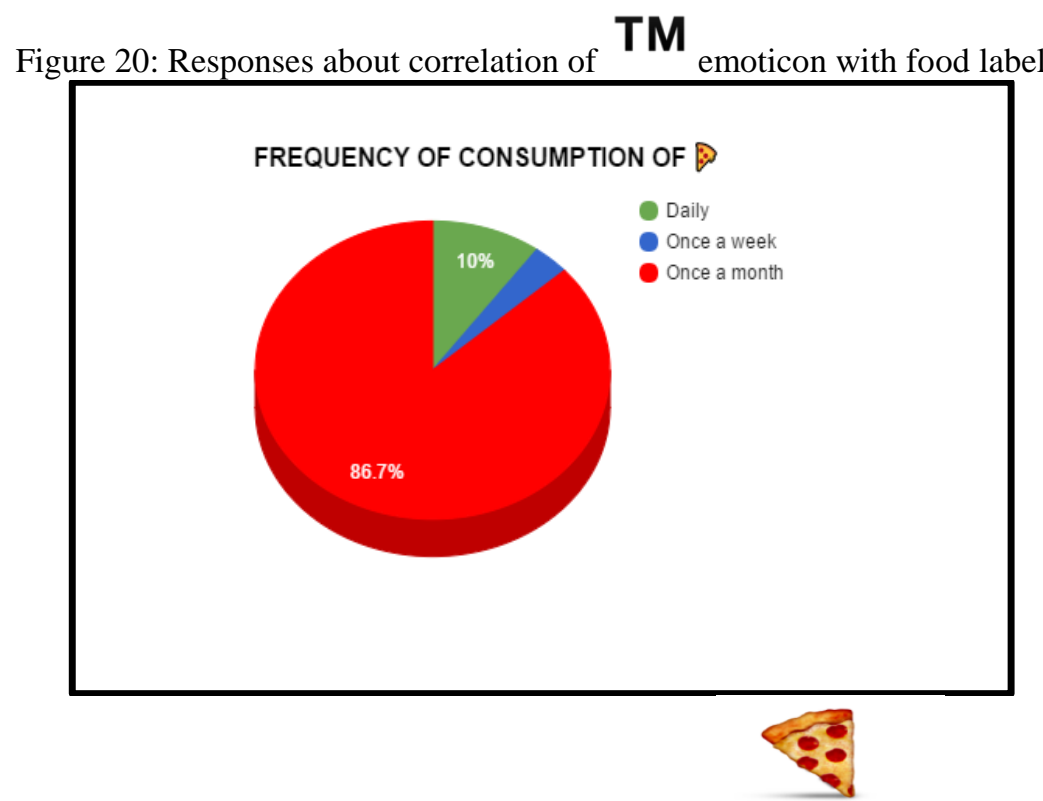

Figure 21: Frequency of consumption of

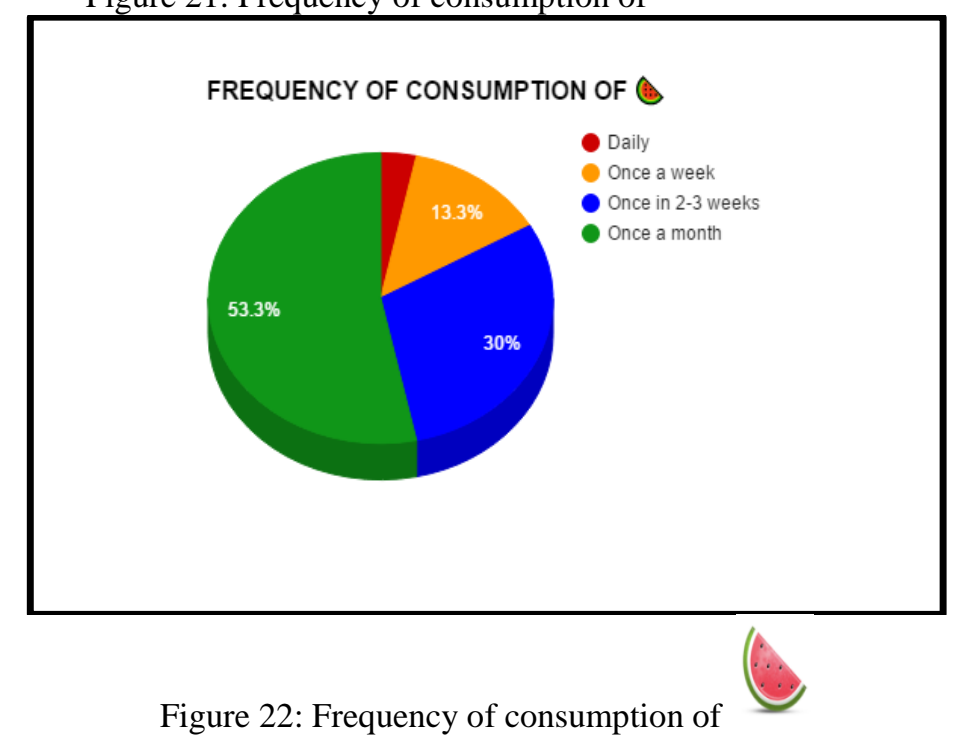




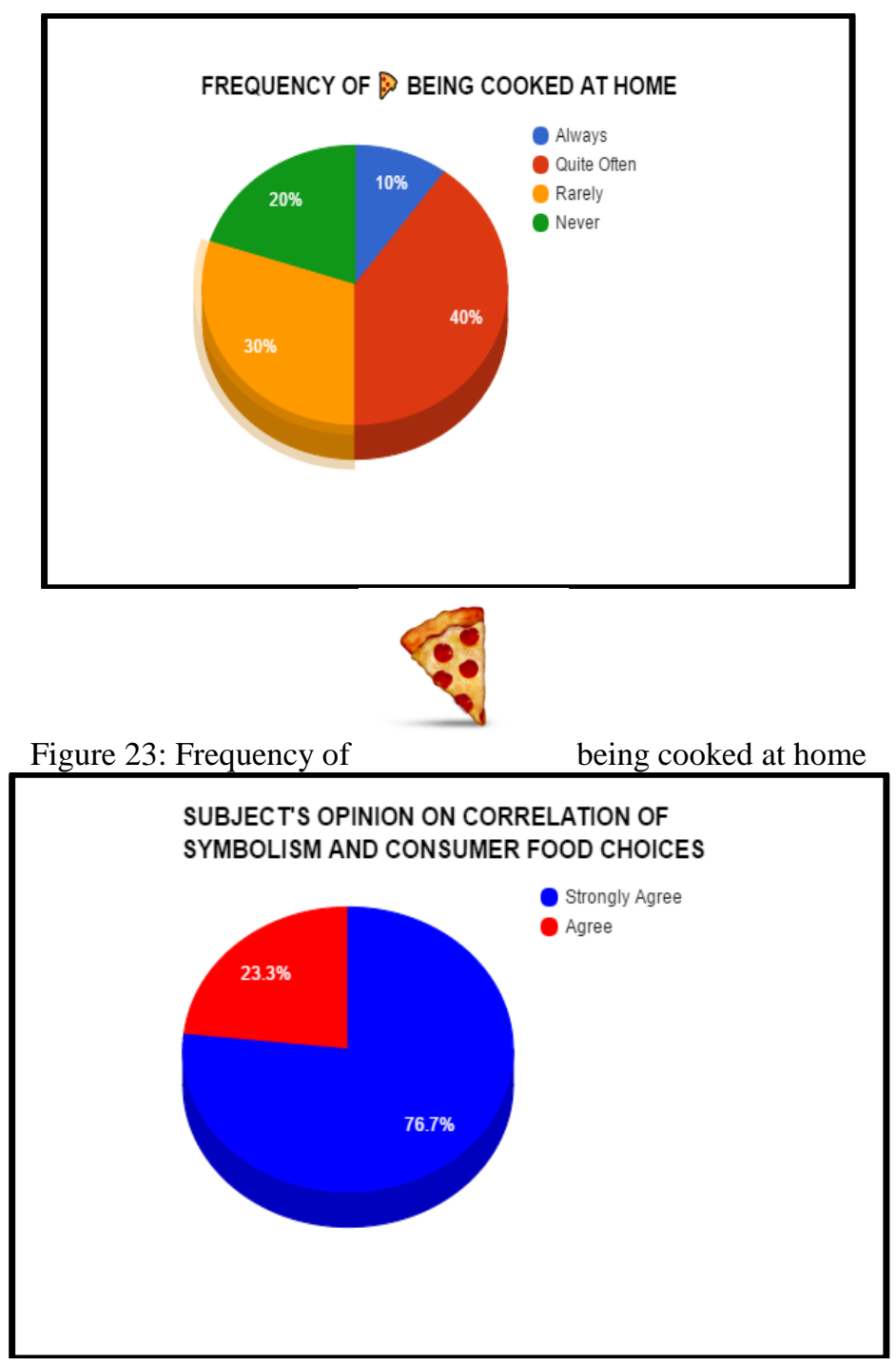

Figure 24 : Subject's opinion on correlation of symbolism and consumer food choices.

\subsection{Results and findings:}

As the area of focus of the current study is food emoticons, majority of the questions were targeted to this topic and the data analysis of the questionnaires led to the following key observations:

- $100 \%$ subjects use WhatsApp and about $46.7 \%$ use it daily.

- $96.66 \%$ subjects use the emoticons in WhatsApp.

- $46.66 \%$ subjects use the food emoticons in WhatsApp every day.

- About $60 \%$ subjects show positive response on eating outside.

- It was observed that $53.3 \%$ subjects prefer a non-vegetarian diet whereas $46.7 \%$ subjects prefer a vegetarian diet.

- $46.7 \%$ of subjects agree on usage of in correlation with food every day.

- $\quad 53.3 \%$ of subjects correlate

with food.

- $53.7 \%$ of subjects correlate with tea, while $43.3 \%$ correlate it with coffee.

- $76.66 \%$ subjects agree on consumption of hot beverages twice a day.

- $40 \%$ of subjects are reminded of a product they consume daily on usage of emoticon.

- $70 \%$ subjects consume bakery products every week. 
- $93.3 \%$ subjects 408 correlate with eating outside and $56.7 \%$ agree about usage of emoticon on food packages.

- $\quad 63.3 \%$ of subjects frequently use emoticon.

- $56.66 \%$ subjects use once a week.

- $46.6 \%$ subjects consume chocolates every week.

- $63.3 \%$ of the subjects are aware about the

- $86.7 \%$ of subjects consume pizza once a month and $40 \%$ subjects have cooked it at home.

- $53.3 \%$ subjects consume watermelon once a month.

- $76.7 \%$ subjects strongly agree on the idea of correlation of symbolism and consumer food choices.

The body of research presented here demonstrated that food can be associated with different emotions with the usage of different emoticons depending on the context where it is imagined to be consumed in, and that the effect that the contexts may exert, depending on the food in question. Thus, the food- related emoticons can be used as a general tool for analysing the emotional responses towards food products and food choices.

The food choices can be governed by the usage of food emotions and vice versa as they have represented a bidirectional relationship. The usage of such emoticons to express feelings regarding food is on a growing scale in this techno-savvy age. Thus, such study can help to get two topics like emotional aspect of food and its effect on food choices get along together and study their interdependence with an emoticon scale. The practical applications of usage of this emoticon scale are seen in the usage of the hedonic scale for measuring food acceptability. Thus, similar other applications can be analysed with the help of such research.

\section{CONCLUSION AND FUTURE PROSPECTIVES}

Food is no more a necessity but has become an integral part of our culture and every celebration. Wishing a friend on his/her birthday with the birthday cake emoticon is a ritual in today's time. Thus, the current study can serve as a mediator in the present knowledge about food emoticons affecting food choices. Emoticons can thus serve as the catalysts in a food to emotion reaction. Sensory and consumer researchers have become more aware of the importance of gathering information regarding how a food/ beverage makes consumers feel, as well as of the importance of considering the consumption context when measuring consumers' perception or liking of a product with the usage of emoticons. However, little has been done to study the effect of the consumption context, and its appropriateness with the product, on emotional responses. The body of research presented here bridged this gap of knowledge and demonstrated that the same food can be associated with different emotions with the usage of different emoticons depending on the context where it is imagined to be consumed in, and that the effect that the contexts may exert varies depending on the food in question. Our results also showed that product-context appropriateness might be a very influential factor for the association of emotional terms to the consumption of a product, and more so than a person's frequency of consumption of the product is also somehow affected by the usage and interdependence of the food product and the emoji used. However, future research should explore this with a wider range of foods, and we believe that this study represents a needed advance in this area of research that could possibly help obtain more accurate emotional responses, closer to those that consumers would feel in real life. With the acceptance of this idea of interdependence of food choices and food likings with symbolism, this can be extended for fields like food packaging, novel product development, product and package designing. The consumer acceptance for these fields should be surveyed and then applied according to consumer preferences. This will thus help the acceptance of any new product with the help of the emoticon rating and thus serve as an important tool for product choices.

\section{ACKNOWLEDGEMENTS}

We, Shruti V. Bendre and Snigdha A. Mathure, students of Ramnarain Ruia College, Mumbai, while presenting this research paper express our feelings of thankfulness to every person who has helped us directly or indirectly to successfully complete this research paper. We acknowledge with gratitude our Principal Dr. Suhas Pednekar for providing the best possible resources in the college. We express our heartfelt indebtedness and owe a deep sense of gratitude to our teacher and guide Dr. (Mrs.) Jyoti D. Vora. Last but not the least, we would like to express our sincere thanks to all the faculty members- Mr. Prashant Masali, Ms. Sneha Pednekar, Ms. Aditi Patwardhan and Ms. Padma Srinivasan for their coordination and cooperation. We would also like to thank the 
non-teaching staff-Mr. Mahesh, Mr. Sandesh and Mr. Trushal of our department for helping us in every possible way. We would also like to extend our gratitude to all our classmates who have helped us in this work.

\section{.REFERENCES.}

[1] C.R. Kothari, Research Methodology Methods And Techniques- 2nd Edition (New Delhi, India; New Age International (P) Ltd. Publishers; ISBN 81-224-1522-9).

[2] Piqueras-Fiszman, B., \& Jaeger, S. R. (2014b). Emotion responses under evoked consumption contexts: A focus on the consumers' frequency of product consumption and the stability of responses. Food Quality and Preference, 35, 24-41.

[3] Piqueras-Fiszman, B., \& Jaeger, S. R. (2014c). The impact of the means of context evocation on consumer's emotion associations towards eating occasions. Food Quality and Preference, 37, 61-70.

[4] Use of emoticon and emoji in tweets for food-related emotional expression. Leticia Vidal, Gastón Ares, Sara R. Jaeger

[5] https://en.wikipedia.org/wiki/Food

[6] https://www.youtube.com/watch?v=cLLDUyy8utY

[7] All emoticons were taken from WhatsApp application 